Article

\title{
The Contextualized Inclusiveness of Parental Leave Benefits
}

\author{
Anna Kurowska \\ University of Warsaw, 00-927 Warsaw, Poland; E-Mail: a.kurowska@uw.edu.pl
}

Submitted: 13 November 2020 | Accepted: 26 May 2021 | Published: 11 June 2021

\begin{abstract}
This article builds on a recent operationalization of inclusiveness of parental leave benefits proposed by Ivana Dobrotić and Sonja Blum and complements it by developing indicators of contextualized inclusiveness. This contextualized approach sets the formal entitlement and eligibility rules of social rights to parental leave benefits in the relevant socio-economic context of the country to which these rules apply. The aim is to shed light on the extent to which parts of the country's population are actually excluded or are at risk of being excluded from access to parental leave at a given moment in time. This is strongly shaped by, among other factors, the structure of the population according to employment status, job tenure or type of contract. An important characteristic of the methodological approach adopted in this article is that the proposed contextualized indicators are based on easily and publicly available and internationally comparable data. This makes the approach easily applicable by wide audiences, academic and practice-oriented ones alike. The proposed indicators are then applied to sixteen European countries and show a much more diversified and nuanced landscape of contextualized inclusiveness of parental leave entitlements in Europe than the comparison of formal inclusiveness done by Dobrotić and Blum suggested. This study also shows that higher formal inclusiveness of employment-based parental leave benefits was more common in countries with higher shares of those social groups that, in case of less inclusive regulations, would not have access to parental benefits.
\end{abstract}

\section{Keywords}

access to leave; inclusive policy; parental benefits; socio-economic context; social indicators; social rights

\section{Issue}

This article is part of the issue "The Inclusiveness of Social Rights: The Case of Parental Leave Policies" edited by Sonja Blum (University of Hagen, Germany) and Ivana Dobrotić (University of Oxford, UK / University of Zagreb, Croatia).

(C) 2021 by the author; licensee Cogitatio (Lisbon, Portugal). This article is licensed under a Creative Commons Attribution 4.0 International License (CC BY).

\section{Introduction}

Early research indicated that access to parenting-related leaves and benefits is particularly contingent on social and labor market inequalities as leave policies, and parental leave benefits in particular, often differently (dis-)advantage various social groups (Koslowski \& Kadar-Satat, 2018; McKay, Mathieu, \& Doucet, 2016). To better understand the potential of parental leave regulations to impact social inequalities in access to parental leave benefits in a comparative perspective, Dobrotić and Blum (2020) last year published a detailed insight into the inclusiveness of parental-leave benefits in Europe. The authors defined parental leave as a care-related right available to both mothers and fathers after the initial maternity/paternity leave (it is understood in the same way in this article). They opera- tionalized the concept of inclusiveness by way of an eligibility index-an aggregated measure based on nine individual indicators (components) proposed by the authors. The index was then applied to a large group of European countries in two points in time (2006 and 2017). This enabled Dobrotić and Blum to show how parental leave regulations changed in time with respect to eligibility rules and how European countries differ by the level of inclusiveness of parental leave regulations. The authors considered both employment-based entitlements and citizenship-based entitlements to parental leave benefits. The criteria for the former entail, for example, minimal job tenure, stability of employment, sector of employment and minimal workingtime/income requirements. The criteria for the latter encompass, for example, a minimal period of residency and means-testing. 
Dobrotić and Blum (2020) offer an important contribution to the comparative literature on parental leave regulations since earlier studies were mostly confined to aspects of parental leave schemes such as the scope of leave rights (leave duration and benefits levels), leave transferability, leave flexibility or gender equality in parental leave systems (see, e.g., Ciccia \& Verloo, 2012; Javornik, 2014; Ray, Gornick, \& Schmitt, 2010; Saxonberg, 2013). Dobrotić and Blum (2020) were the first to thoroughly analyse the aspect of inclusiveness of parental leave benefits based on detailed entitlement and eligibility criteria.

However, the individual eligibility indicators and the aggregate index of inclusiveness Dobrotić and Blum propose are all based strictly on legal (formal) regulations of parental leave entitlements. Similarly, the majority of the aforementioned earlier comparative studies on parental leaves used indicators based solely on legal/formal parental leave regulations. Such an approach sets aside the country's socio-economic context, e.g., the employment structure of the population, which is crucial for assessing the size of the parts of the population that are in fact included/excluded from having the opportunity to take advantage of parental leave benefits in a given country at a given moment in time. When only formal regulations are taken into consideration, two countries with the same parental leave regulations-e.g., providing only employment-based benefits with similar eligibility criteria - would be assessed as having the same level of inclusiveness. But if they differ substantially in the structures of their populations by employment status, in one of these two countries the share of people that would in fact have access to parental leave benefits could be much larger than in the other. Furthermore, parental leave regulations in one country may be assessed as less inclusive than in another country due to stricter eligibility criterion, e.g., longer job tenure requirement. But if the employment structure of the population by job tenure in this country is much more 'favourable' than in the other country (i.e., there is a much larger share of employees with long job tenure), this may result in a similar or even larger share of people that would in fact have access to parental leave benefits. Thus, to better understand the inclusive/exclusive potential of a certain parental leave system in a given society (population) at a given moment in time, the socio-economic context must also be taken into account. This is particularly important when less inclusive (more restrictive) parental leave regulations are compared.

European countries differ considerably by socioeconomic context, including not only their employment structures, but also other aspects that are relevant for diverse entitlement or eligibility criteria of parental leave architectures (such as share of non-citizens or the income structure of the population; see, e.g., Eurostat, 2020). Therefore, comparison of entitlement and eligibility criteria in parental leave regulations in European countries may not adequately reflect the differences in the extent to which their parental leave systems actually include/exclude parts of the country's population from access to parental leaves in a given moment in time.

The first aim of this article is thus to modify/contextualize the indicators proposed by Dobrotić and Blum (2020) to bring the comparative assessment of inclusiveness of parental leave benefits in European countries closer to the assessment of contextualized inclusiveness. I contextualize the authors' original indicators by incorporating measures of the socio-economic context into the indicators (the details are explained in Section 3). I build directly on Dobrotić and Blum indicators to enable direct comparison between their results (i.e., comparative assessment of formal inclusiveness) with the contextualized assessment of the inclusiveness of parental leave benefits. This is also why I apply the proposed contextualized indicators to the same group of 16 European countries as Dobrotić and Blum (2020; the authors calculated the values of indicators of inclusiveness only for these 16 countries: Austria, Belgium, Croatia, Chechia, Denmark, Estonia, Finland, France, Germany, Hungary, Iceland, Italy, Norway, Portugal, Slovenia and Sweden). I also use data for the same reference year (2017).

Based on the comparison between the results from original and contextualized indicators I discuss the role of the crucial aspects of the socio-economic context of the 16 countries for the differences between the countries in contextualized inclusiveness of parental leave benefit schemes (the second aim of this article). I ask two research questions. First, within the group of countries that score the same (and rather low) at a particular dimension of formal inclusivity of parental leave benefits, do we observe (quite) similar or diverse socioeconomic contexts? The second question is whether socio-economic context exacerbates or diminishes the differences between countries that already exist in formal inclusiveness? In other words, are less inclusive parental leave entitlements found in countries where social groups with certain characteristics that make them ineligible for parental leave benefits (in these countries), comprise a larger or smaller share of the population than social groups with the same characteristics in the countries with more inclusive regulations? The answers to these questions help me formulate conclusions about the importance of contextual analysis for the assessment of inclusiveness of parental leave schemes in Europe.

\section{Contextualized Comparative Analysis of Parental Leave Systems: Earlier Studies}

Few published studies have compared parental leave entitlements while acknowledging the differences in the socio-economic context in which the leave entitlements are implemented.

Using EU-SILC microdata, Bártová and Emery (2018) explored the heterogeneity in the actual financial support (i.e., generosity) of parental leave benefits within 
European countries by applying parental-leave rules to the socio-economic structure of the populations in question. Their results reveal far greater heterogeneity in generosity (compensation rate) of leave policy entitlements in the analysed countries than existing indicatorsbased on formal regulations-had suggested. However, the study did not assess the inclusiveness of parental leave schemes.

Javornik and Kurowska (2017) proposed indicators for comparative analysis of parental leave entitlements (see also Kurowska \& Javornik, 2019). They incorporated both formal features of parental leave regulations and the features of the socio-economic context in given countries (e.g., living standards, gender pay gap, average wages). The aim of the study was to compare the 'real opportunities' for equal parental involvement in the raising of children across gender and income lines in European countries (Javornik \& Kurowska, 2017, p. 624). The authors argued that fathers are more sensitive to any income loss than mothers, and that the level of the potential income shock caused by the use of parental leave determines whether fathers take the leave at all. The negative effect of the income shock depends not only on the earnings replacement rate by parental leave benefit, but also on the living standards, i.e., a low replacement rate is financially more viable in a more affluent society than in a less affluent one. Therefore, according to the authors, in order to compare the 'real opportunities' the non-transferable parental leave (father quota) create for fathers in different countries, it is indispensable to include the living standards in these countries in the analysis. The authors also argued that, where the transferable parts of parental leave are concerned, not only living standards, but also gender pay gaps must be taken into consideration. This is because the higher the gender pay gap is, the higher the relative income loss will be if the father, instead of the mother, takes the leave. Javornik and Kurowska (2017) showed that including the socio-economic context in the analysis of parental leave benefits reveals a much more nuanced and diversified reality of opportunities that parental leave systems create for parents in Europe, than comparison of parental leave regulations suggests. However, Javornik and Kurowska (2017) and Kurowska and Javornik (2019) did not provide an assessment of the inclusiveness of parental leave schemes that would refer to the numerous eligibility criteria in parental leave schemes, which together with the socio-economic structure of the population may exclude large groups of people from access to parental leave benefits in the first place.

Using EU-LFS and EU-SILC microdata, O'Brien, Connolly, and Aldrich (2020) analysed eligibility for paid and unpaid statutory parental leave (jointly) across populations of 'potential' parents (people aged 20-49 years) in the EU-28. Applying the rules of parental leave entitlements to European populations, they showed that the share of eligible parents varied considerably across the EU member states-again, greater than the sole com- parison of policy regulations had indicated. Their study brings the comparative analysis of parental leave systems very close to the idea of measuring the differences in contextualized inclusiveness, as it directly simulates the share of eligible population of 'potential parents' for parental leaves in each EU Member State. However, their study does not analyse the inclusiveness of parental leave benefits, as it considers paid and unpaid parental leaves jointly. Moreover, their simulation does not consider all nine aspects of formal inclusiveness identified by Dobrotić and Blum (2020). This means that their findings (on contextualized inclusiveness) and the results obtained by Dobrotić and Blum (on formal inclusiveness) cannot be directly compared. Furthermore, the authors do not analyse the relationships between the socio-economic context and the eligibility rules. Instead, they focus on comparing the importance of different reasons for ineligibility in different countries.

This article extends previous studies in the field by offering the first comparable methodology and empirical analysis of the contextualized inclusiveness of parental leave benefits, based on the nine detailed criteria of eligibility in parental leave entitlements applied in the analysis of formal regulations by Dobrotić and Blum (2020).

\section{Contextualized Indicators of Inclusiveness of Parental Leave Benefit Schemes}

Each indicator proposed by Dobrotić and Blum relates to one aspect/dimension of the eligibility rules with respect to the 'obligations' side of the social rights relationship (Clasen \& Clegg, 2007) in the sphere of parental leave benefits. They are focused solely on statutory parental leave benefit entitlements at the state level (baseline leave provision of social rights related to paid leave) and consider both employed (employmentbased entitlements) and parents as such, including unemployed/inactive parents (citizenship-based entitlements). Each indicator is given a range of scores that a particular country's parental leave benefit regulations can achieve. The higher the score, the more inclusive the particular dimension is considered to be. The first six dimensions/indicators refer to eligibility conditions of employment-based criteria, and the other three to citizenship-based criteria (see Table A1 in the Supplementary File).

Below, I contextualize each individual indicator so it becomes sensitive to crucial aspects of the socioeconomic context (structure) of the population. I do this by choosing the most relevant contextual reference in each case. In some cases, where no data is available to directly refer to the structure of the population according to the entitlement criteria of parental leave regulations, a relevant indirect indicator (a proxy) is proposed. These indirect indicators are employed to grasp the socio-economic or institutional conditions that impact the vulnerability of the respective population to non-compliance with particular criteria of parental leave 
regulations. In other words, if there is no data available that would provide us with direct information on the share of population that does not meet the eligibility requirements set in parental leave regulations, I turn to the most relevant indirect indicators that shed light on the risk that substantive parts of the population do not meet these requirements.

Following the approach adopted in Javornik and Kurowska (2017) and Kurowska and Javornik (2019), an important characteristic of the proposed methodological approach in this article is the creation of indicators which use easily and publicly available and internationally comparable data (from OECD, Eurostat and ILOSTAT and MIPEX databases), making the approach easily applicable by a wide, not only academic audience.

\subsection{Employment Tenure Requirement}

The first basic criterion in employment-based entitlements is the previous length of employment needed to be eligible for parental leave benefit. In the original version of the relevant indicator by Dobrotic and Blum (2020), the highest score (5) is given to countries where, in order to be eligible, one must be employed just before the leave starts (i.e., there is no employment tenure required). Then, the longer the required term in employment, the lower the score, with 1 being assigned to countries demanding twelve or more months of employment tenure to be entitled to parental leave benefit. Zero is given to countries without employment-based benefits. The scores are in integer form only.

This indicator is contextualized based on insight into the structure of employment by job tenure in the country under assessment. Data on the share of the employed according to job tenure, with grouping resembling the categories identified by Dobrotić and Blum (2020), is readily accessible in the OECD database. The assumption behind the contextualization of this indicator is straightforward, following the logic adopted in O'Brien et al. (2020), Javornik and Kurowska (2017) and Kurowska and Javornik (2019) in their studies: The higher the share of employees that do not meet the eligibility criteria, the lower the contextualized inclusiveness of parental leave benefit in the country. The maximum value of 5 points (ideal situation) is given to two country types: those where there is no employment tenure required and those that have a tenure requirement but where there is no one among the employees who would not adhere to this requirement. For example, if in country $X$ there is a requirement of at least 3 months of job tenure but the percentage of employed people in the country with shorter job tenure is equal to 0 , this country would still score 5 on the contextualized inclusiveness. The number of points will decrease as the share of employed people that do not meet the tenure requirement in the population increases. Country where no employed person would adhere to the criterion of job tenure adopted in this country receives 0 points.
The formula for the indicator of the contextualized employment tenure inclusivity (CETI) is the following:

$$
\mathrm{CETI}_{i}=5-\left(5 \times \mathrm{SENE}_{i}\right)
$$

$i$ denotes the country under assessment (this applies to all the formulas proposed in the article); $S E N E_{i}$ denotes the share of employed persons with job tenure shorter than the tenure requirement to be eligible for parental benefit in country $i$ (a share is expressed as a decimal fraction and this applies to all formulas in this article); $S E N E_{i}=0$ if there is no tenure requirement in the eligibility criteria for parental leave benefit in country $i$.

CETI ranges from 0 to 5 . But in contrast to the original indicator, it may take all real numbers in that range as well as integer values. The construction of the indicator enables a nuanced assessment of the inclusiveness for two countries with the same job tenure requirement but different shares of employed persons that do not adhere to the job tenure eligibility criterion. But it also enables the more 'favourable' structure of the employed population (higher share of employees with long job tenure) to 'make up' for the stricter eligibility criteria. To illustrate, I will take two countries: $X$ and $Y$. Country $X$ has a minimum of 8 months of job tenure requirement while country $Y$ has a minimum of 3 months. Country $Y$ would score higher ( 3 points) than country $X$ ( 2 points) on the original indicator proposed by Dobrotić and Blum (2020), as the requirement in country $X$ is stricter than in country $Y$. However, if the share of employed persons with job tenure shorter than 8 months in country $X$ is 10 percent and the share of the employed persons with job tenure shorter than 3 months in country $Y$ is 20 percent, then a higher share of people that are not eligible for parental leave benefit due to not adhering to the job tenure criterion will be found in country $Y$ than in country $X$. This would be mirrored in the value of CETI for these countries, as country $X$ would score 4,5 and country $Y$ would score 4 . This is how CETI reflects the contextualized, rather than formal inclusiveness of parental leave benefit eligibility criterion related to job tenure.

\subsection{Employment Non-Interruption Requirement}

The second requirement in employment eligibility rules that can be observed in some countries is the inadmissibility of interruptions in the employment track. The original indicator proposed by Dobrotić and Blum (2020) relating to this requirement takes only two values: the value of 1 when the interruptions are allowed (or the condition is not applicable as in the case of countries that score 5 on the first indicator), and the value of 0 , when interruptions are not allowed. In order to contextualize this indicator along the lines of the theoretical approach adopted in this study, insight into the actual situation of employed persons in the country according to continuity/interruptibility of their employment careers would be needed. Unfortunately, there is no data on this 
aspect collected in the available databases with comparable information for European countries.

However, one's type of contract may be considered a reliable indirect indicator of the vulnerability of the individual employment situation to interruptions, with temporary contract indicating a much higher level of vulnerability to interruptions than a permanent contract (see, e.g., de la Porte \& Emmenegger, 2017). Research shows that fixed-term contracts significantly increase the risk of finding another temporary job after termination of the contract often preceded by a period of unemployment (see, e.g., Gagliarducci, 2005; Giesecke \& Groß, 2003; Sanz, 2011). Therefore, the information on the share of employees on temporary contracts, which is also readily available in the OECD and Eurostat databases, would be a reasonable indicator of vulnerability of the employed persons in the country to employment interruptions, and thus important when assessing the contextualized inclusiveness of parental leave benefit eligibility rules in this respect.

Like employees on temporary contracts, permanent employees can also experience employment interruptions (and are at some risk of dismissal). Thus, the assessment of the level of this risk (which may differ between countries) should be taken into consideration as well when constructing the contextualized indicator. There is, however, no data on the level of this risk in the available, internationally comparable databases. Nevertheless, it has been shown that the risk of contract termination for workers on permanent contracts highly depends on the strictness of standard employment protection in the country (see OECD, 2020). The higher the protection, the lower the risk of layoffs and worker flows (OECD, 2020; see also Boeri \& Jimeno, 2005; Gielen \& Tatsiramos, 2012; Haltiwanger, Scarpetta, \& Schweiger, 2014; Pages \& Micco, 2012). It has also been argued that more protective employment regulations enable smoother transition to the next job (OECD, 2020). Therefore, the index of regular employment protection-available in the OECD database-would be a reasonable indirect indicator of the vulnerability of permanent employees to employment interruptions. The OECD index of strictness of individual employment protection for regular contracts (hereafter IS) ranges from 0 to 6 . The higher the value, the stricter the regulations on dismissals and the more difficult it is for the employer to lay off employees. Therefore, the higher the value of IS, the higher the stability of regular employment in the country will be (OECD, 2020).

The indicator contextualized employment interruption inclusivity (CEII) that I propose would be equal to 1 if the country does not have a non-interruption requirement; otherwise it is calculated according to the following formula:

$$
C E I_{i}=1-\left(1-\frac{I S_{i}}{6}+S E T_{i}\right)
$$

$S E T_{i}$ is the share of employees on temporary contracts in country $i$ and $I S_{i}$ is the OECD index of strictness of employment protection for individual employees on regular contracts in country $i$.

This indicator ranges between 0 and 1 . The maximum value of CEll would go to two types of country: those without non-interruption requirement and those that have this requirement but where there are no employees on temporary contracts $\left(S E T_{i}=0\right)$ and where protection of employment for employees on regular contracts is the highest possible $\left(I S_{i}=6\right)$. The higher the share of employees on temporary contracts (SET), the lower the value of the CEII. Furthermore, the higher the value of IS, the higher the CEII. As SET and IS relate to separate segments of the employed population, the values of SET and inversed relative IS value with reference to the maximum value of IS possible (6) are added together.

\subsection{Employment Stability with Single-Employer Requirement}

The third requirement in employment eligibility rules found in some countries is the provision that the employment period must be accumulated with the same employer. Here, the original indicator takes the value of 0 when that is the case and the value of 1 when the employment condition can be fulfilled with different employers (or the condition is not applicable as in case of countries that score 5 on the first indicator). The logic behind the contextualization of this indicator is identical to CEII, as 'non-interruption' and 'same employer' restrictions have a very similar meaning: They disadvantage those at risk of dismissal or change of job due to temporary contract. The indicator of contextualized employment accumulation inclusivity (CEAl) is thus constructed in the same way as CEII but differs in that the default value of 1 is assigned to countries without no single employer requirement. For those countries that do have this requirement, the value of CEAI is calculated based on the formula given below (which mirrors the formula of CEII and thus has the same properties):

$$
C E A I_{i}=1-\left(1-\frac{I S_{i}}{6}+S E T_{i}\right)
$$

$S E T_{i}$ is the share of employees on temporary contracts in country $i$ and $I S_{i}$ is the OECD index of strictness of employment protection for individual employees on regular contracts in country $i$.

\subsection{Differentiation by Form of Employment}

The fourth component of eligibility rules for employment-based benefits, considered by Dobrotić and Blum, was whether the parental leave benefit scheme was differentiated between employees and the self-employed. If both groups were included in the same scheme, the score was 2. If the self-employed had a separate scheme and were subject to stricter eligibility criteria or lower 
benefits, the score was 1 . If the self-employed were excluded from the parental leave benefit entitlements, the score was 0 .

In line with the theoretical concept of contextualized inclusiveness proposed in this article, I propose to contextualize this indicator by looking at the structure of the employment in the countries that do have a separate scheme for self-employed or do not have a parental leave scheme for this group at all. The higher the share of the self-employed in working population in such countries, the lower the contextualized inclusiveness of the parental leave provisions in the eligibility dimension under discussion would be. The formula for the indicator of contextualized inclusiveness in the form of employment (CIFE) is thus the following:

$$
\mathrm{CIFE}_{i}=I_{4 i}-S S E_{i}
$$

$I_{4 i}$ is the original value of the fourth indicator from Dobrotić and Blum's list for country $i$; $S E E_{i}$ is the share of the self-employed in total employment in the country $i$, but $S E E_{i}=0$ if in the country under assessment the self-employed are not treated differently than those employed by others.

\subsection{Sectoral Differentiation}

The fifth eligibility criterion considered by Dobrotić and Blum was the differentiation of parental leave benefit entitlement rules between sectors. The score was 1 if there was no differentiation, and 0 if there was. As with CIFE, the contextualization of the indicator I propose is straightforward and relies on the insight into the share of employment in the sectors of the economy that have separate schemes subject to stricter eligibility criteria/lower benefits. The formula for the indicator of contextualized inclusiveness by sector of employment (CISE) is the following:

$$
C I S E_{i}=1-S E S_{i}
$$

SES $S_{j}$ is the share of the employees in the sector, which is treated more strictly than other sectors in the country $i$ (data on employment shares in different economic sectors are available for most countries in the ILOSTAT database). If there is no sector that is treated more strictly than other sectors in the parental leave regulations, or there are no employees in the sectors that are treated differently in the economy, then $S E S_{i}=0$.

\subsection{Working-Time/Minimum Income Requirement}

The sixth indicator of eligibility regulations proposed by Dobrotic and Blum pertained to the presence of the requirement of a certain level of working time/earnings needed to be eligible for parental leave benefit. If no conditions were present, the score was 1 . Where there were requirements, the score was 0 .

In order to contextualize this indicator in a straightforward manner, the share of workers that do not meet the working-time/minimum income criteria in the relevant countries would have to be available. Unfortunately, there is no such data in publicly available and internationally comparable databases, so other contextual measures had to be used as relevant proxies.

According to the literature, part-time employees are the vulnerable to both not meeting the criteria of minimum working time and the minimum income requirement (see, e.g., Horemans, Marx, \& Nolan, 2016). Part-time workers not only earn less because they work less, but also because they face wage penalty that is partially driven by occupational segregation (Bardasi \& Gornick, 2008; O'Dorchai, Plasman, \& Rycx, 2007). The advantage of using the share of part-time workers to contextualize the indicator of inclusiveness of parental leave benefits in the dimension pertaining to workingtime/minimum income requirement, is that the data on the share of employees working part-time are publicly available in all major internationally comparable data sources, including Eurostat, OECD or ILOSTAT databases.

The formula for the indicator of contextualized working-time/income inclusiveness (CWTI) is the following:

$$
C W T I_{i}=1-S^{2} P E_{i}
$$

$S P T E_{i}$ is the share of part-time workers in total employment in country $i$; but if country $i$ does not have the minimum working time/income requirement in parental leave regulations, then $S P T E_{i}=0$.

\subsection{Residency Period Requirement}

The seventh indicator proposed by Dobrotić and Blum (2020) pertained to the citizenship/residency based parental leave benefit provisions. Its values ranged from 0 to 3 . Countries without citizenship/residency-based benefits received a 0 . Other values were assigned to countries with such benefits; and the shorter the period of residency required, the higher the value of the indicator. Three points were assigned to countries which required residency only at the time of the child's birth.

The straightforward contextualization of this indicator is hampered by the unavailability of internationally comparable data on the share of people not meeting the residency-period criteria. Therefore, other contextual measures had to be used as relevant proxies. As the only group vulnerable to potential non-eligibility for parental leave benefits due to lack of residency are non-citizens in the country, the first measure included in the contextualized indicator is the share of non-citizens in the population of the country under assessment (the data are available in Eurostat). Furthermore, as the residency policies of European countries tend to differ substantially (see Huddleston, Bilgili, Joki, \& Vankova, 2015) and this may significantly impact the eligibility of non-residents for citizenship-based parental leave benefits, another element introduced into the contextualized indicator proposed is the MIPEX measure of permanent residency policy (available at www.mipex.eu). The MIPEX indicator of 
permanent residency policy assesses how easy it is to gain access to permanent residency for migrants in a particular country (the higher the value, the easier the access; the values range from 0 to 100). The formula for the indicator of contextualized residency inclusiveness (CRI) is therefore the following:

$$
C R I_{i}=I_{7 i}-\left(1-\frac{M P R_{i}}{100}\right) \times S M_{i}
$$

$I_{7 i}$ denotes the original value for the seventh indicator from Dobrotić and Blum's list in country $i$; $M P R_{i}$ is the value of the MIPEX measure of permanent residency policy for country $i$; and $S M_{j}$ is the share of non-citizens to the total population in country $i$.

\subsection{The Exclusion of Some Groups}

The eighth indicator proposed by Dobrotic and Blum also referred to citizenship-based criteria and identified whether the parental leave regulations explicitly exclude some groups (e.g., long-term or not officially unemployed), as these entitlements may also be selective and bound to additional criteria (e.g., registration with an unemployment service). Those that do not exclude any groups received a score of 1 , while those that do received a 0 . The contextualization of this indicator is based on identification of the share of people that belong to the excluded group in a particular country (all data on the excluded groups-e.g., the long-term unemployed or non-registered unemployment - that can be identified in parental leave regulations in European countries is available in the Eurostat/LFS databases). The formula for the indicator of contextualized group inclusiveness (CGI) is the following:

$$
C G I_{i}=1-S E G_{i}
$$

$S E G_{i}$ is the share of the excluded group in the population of country $i$; and $S E G_{i}=0$ if there is no means-testing applied in the eligibility criteria for parental leave benefit in country $i$.

\subsection{Means Testing}

The last indicator on Dobrotić and Blum's list was identifying the presence of means testing in parental leave benefit citizenship-based entitlements. Countries in which means test applies received 0 points, while those in which it does not received 4 . The straightforward contextualization of this indicator is hampered by the unavailability of internationally comparable data on the shares of people with incomes higher than the national meanstesting thresholds (i.e., ineligible for the benefits according to this criterion). Therefore, another contextual measure had to be chosen as a relevant proxy. The Eurostat database provides information on the levels of income thresholds for 40, 50, 60 and 70 percent of the median equivalized income in the country and poverty rates for each threshold. This makes it quite simple to calculate the share of people in a country with income above the poverty threshold which has the closest value to the means-testing threshold applied for the citizenshipbased parental leave benefit. The formula for the indicator of contextualized means-testing inclusiveness (CMT) is the following:

$$
\mathrm{CMTI}_{i}=4-\left(4 \times \mathrm{SPAT}_{i}\right)
$$

$S P A T_{i}$ is the share of people with income above the poverty threshold closest to the level of means-testing threshold applied for the citizenship-based parental leave benefit in country $i$ but SPAT $T_{i}=0$ if country $i$ does not apply a means-test and $S P A T_{i}=1$ if it does not offer citizenship-based benefits.

\section{Empirical Application: Comparative Assessment of Contextualized Inclusiveness of Parental Leaves in Europe}

This section provides the calculations of the values of all contextualized indicators proposed above for the same group of countries and the same reference (the latter) year (2017) as Dobrotić and Blum (2020, p. 27) using relevant measures from OECD, Eurostat, ILOSTAT and MIPEX databases. It then compares them with original values for original indicators of formal inclusiveness. Table 1 provides the original results from Dobrotić and Blum (2020) and the results of my calculations. All the values of measures used to calculate the contextualized scores for each indicator are available upon request.

For nearly all dimensions of eligibility in employmentbased parental leave entitlements, the homogenous groups of countries with a relatively low level of formal inclusiveness were highly diversified in terms of contextualized inclusiveness. This means that similar restrictions may in practice exclude smaller or larger parts of the population from access to parental leave benefits in a given country at a given time. I also found evidence that in some aspects of eligibility rules of employment-based entitlements (related to job tenure and self-employment status), higher formal inclusiveness of parental leave benefit entitlements was more common in countries with 'less favourable' socio-economic context, i.e., higher shares of those social groups that would not have access to parental benefits if the regulations were less inclusive.

This study has also revealed that in contrast to employment-based parental leave entitlements, the socio-economic context is much less important for assessing contextualized inclusiveness of citizenshipbased entitlements.

Below, I offer a detailed comparison between formal and contextualized inclusiveness separately for each individual indicator as well as for the composite index.

\subsection{Employment-Based Parental Leave Entitlements}

In the original classification, according to the scores assigned by Dobrotić and Blum (2020), four groups of 
Table 1. Original scores from Dobrotić and Blum (2020) and the scores for contextualized indicators for nine dimensions of inclusiveness of eligibility rules in parental leave benefits provisions in 16 European countries (data for 2017).

\begin{tabular}{|c|c|c|c|c|c|c|c|c|c|c|c|c|c|c|c|c|c|c|}
\hline & \multicolumn{12}{|c|}{ Employment-based benefits requirements } & \multicolumn{6}{|c|}{ Citizenship-based benefits requirements } \\
\hline & \multicolumn{2}{|c|}{$\begin{array}{l}\text { Employment } \\
\text { tenure }\end{array}$} & \multicolumn{2}{|c|}{$\begin{array}{l}\text { Employment } \\
\text { interruption }\end{array}$} & \multicolumn{2}{|c|}{$\begin{array}{l}\text { Same } \\
\text { employer }\end{array}$} & \multicolumn{2}{|c|}{$\begin{array}{l}\text { Form of } \\
\text { employment }\end{array}$} & \multicolumn{2}{|c|}{$\begin{array}{l}\text { Sectoral } \\
\text { differentiation }\end{array}$} & \multicolumn{2}{|c|}{$\begin{array}{l}\text { Working- } \\
\text { time/income }\end{array}$} & \multicolumn{2}{|c|}{ Residency } & \multicolumn{2}{|c|}{$\begin{array}{l}\text { Groups } \\
\text { exclusion }\end{array}$} & \multicolumn{2}{|c|}{ Means-testing } \\
\hline & 11 & CETI & 12 & CEII & 13 & CEAl & 14 & CIFE & 15 & CISE & 16 & CWTI & 17 & CRI & 18 & CGI & 19 & CMTI \\
\hline Austria & 3 & 4.55 & 0 & 0.29 & 1 & 1 & 2 & 2 & 1 & 1 & 1 & 1 & 3 & 3 & 1 & 1 & 4 & 4 \\
\hline Belgium & 1 & 4.41 & 1 & 1 & 0 & 0.24 & 0 & -0.17 & 0 & 0.22 & 1 & 1 & - $^{*}$ & -* $^{*}$ & - $^{*}$ & $-^{*}$ & - $^{*}$ & 0 \\
\hline Croatia & 1 & $-^{*}$ & 1 & 1 & 1 & 1 & 2 & 2 & 1 & 1 & 1 & 1 & 1 & $\approx 1$ & 0 & 0.99 & 4 & 4 \\
\hline Chechia & 2 & 4.46 & 1 & 1 & 1 & 1 & 1 & 0.86 & 1 & 1 & 1 & 1 & 3 & 3 & 0 & $-^{*}$ & 4 & 4 \\
\hline Denmark & 4 & 4.77 & 1 & 1 & 1 & 1 & 1 & 0.94 & 1 & 1 & 0 & 0.79 & 3 & 3 & 0 & - $^{*}$ & 4 & 4 \\
\hline Estonia & 5 & 5.00 & 1 & 1 & 1 & 1 & 2 & 2 & 1 & 1 & 1 & 1 & 3 & 3 & 1 & 1 & 4 & 4 \\
\hline Finland & 3 & 4.37 & 0 & 0.17 & 1 & 1 & 2 & 2 & 1 & 1 & 1 & 1 & 2 & 1.99 & 1 & 1 & 4 & 4 \\
\hline France & 1 & 4.57 & 0 & 0.25 & 0 & 0.25 & 1 & 0.90 & 1 & 1 & 1 & 1 & 3 & 3 & 1 & 1 & 0 & 0.12 \\
\hline Germany & 5 & 5.00 & 1 & 1 & 1 & 1 & 2 & 2 & 1 & 1 & 1 & 1 & 3 & 3 & 0 & 0.98 & 4 & 4 \\
\hline Hungary & 1 & 4.33 & 1 & 1 & 1 & 1 & 2 & 2 & 1 & 1 & 1 & 1 & 3 & 3 & 1 & 1 & 4 & 4 \\
\hline Iceland & 3 & 4.41 & 0 & 0.15 & 1 & 1 & 2 & 2 & 1 & 1 & 0 & 0.80 & 1 & 0.97 & 1 & 1 & 4 & 4 \\
\hline Italy & 5 & 5.00 & 1 & 1 & 1 & 1 & 1 & 0.76 & 0 & 0.85 & 1 & 1 & 3 & 3 & 1 & 1 & 0 & 0.35 \\
\hline Norway & 3 & 4.61 & 1 & 1 & 1 & 1 & 2 & 2 & 1 & 1 & 0 & 0.77 & 3 & 3 & 1 & 1 & 4 & 4 \\
\hline Portugal & 3 & 4.55 & 1 & 1 & 1 & 1 & 2 & 2 & 1 & 1 & 1 & 1 & 3 & 3 & 0 & ---* & 0 & 0.3 \\
\hline Slovenia & 5 & 5.00 & 1 & 1 & 1 & 1 & 2 & 2 & 1 & 1 & 1 & 1 & 3 & 3 & 1 & 1 & 4 & 4 \\
\hline Sweden & 2 & 3.95 & 0 & -0.12 & 1 & 1 & 2 & 2 & 1 & 1 & 0 & 0.78 & 3 & 3 & 1 & 1 & 4 & 4 \\
\hline
\end{tabular}

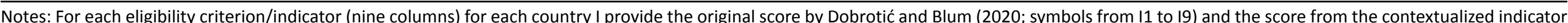
(symbols from CETI to CMTI); *data not available. 
countries were characterized by levels of strictness of the required employment period needed to be eligible for parental leave. Within each group I found substantial differentiation of contextualized inclusiveness, as countries within each group differed in the shares of employees not adhering to the employment tenure criterion. What is more, I found a moderate linear negative correlation between formal inclusiveness of employment tenure requirements and the share of employees that do not meet the employment tenure requirements $(r=-0.518 ; p=0.048)$. This means that the employment structure by job tenure makes up, to some extent, for the stricter eligibility criterion of job tenure in parental leave regulations. To put it differently, more inclusive job tenure requirements in employment-based entitlements 'compensate' to some extent the 'less favourable' structure of the employees by tenure in the sixteen countries under analysis. Interestingly, Sweden, which originally scored 2 (thus higher than France, Croatia, Hungary and Belgium) achieved the lowest contextualized score among all the countries (see Table 1).

In the case of the second employment-related requirement (non-interruption of employment), Dobrotić and Blum identified five countries that got the same zero score. This group is again well diversified when it comes to contextual inclusiveness, but there is no clear relationship between the existence of this criterion in parental leave entitlements and the structure of the employed by type of contract. The average share of workers on temporary contracts in countries scoring 0 on the original indicator was slightly higher (13.7 percent) than for countries scoring 1 (12.84 percent), but this difference was not statistically significant. Again, Sweden got the lowest CEII score $(-0.12)$, due foremost to the relative preponderance of employees its labour market had on temporary contracts.

According to the third employment-related criterion (accumulation of employment with the same employer) two countries were originally given a score of zeroBelgium and France. The contextualization of this result with the CEAl indicator brought only a small changethese two countries scored 0.24 and 0.25 , respectively. Furthermore, I haven't found statistically significant differences in the average values of context variables between the two groups identified by Dobrotic and Blum (2020).

I found a highly diversified contextual inclusiveness among five countries that scored 1 on Dobrotić and Blum's criterion of different treatment of the selfemployed. What is more, I found a moderate negative correlation $(r=-0.38 ; p=0.0003$ ) between the original score for this indicator (formal inclusiveness) and the share of self-employment in the country. It can therefore be concluded that lower inclusivity of formal regulations with respect to the self-employed is on average 'compensated' by a lower share of the self-employment in the economy.

When it comes to the sectoral differentiation in entitlement to parental leave benefits, Belgium and Italy received a score of zero in the original scoring. In Belgium, workers in the private (for profit) sector were treated more restrictively than workers in the non-profit sector. In Italy, workers enrolled in Gestione Separata compared to other workers. According to the contextualized indicator (CISE), Belgium scored much lower (0.22) than Italy (0.85); While the share of workers in the less advantaged sector is higher in Belgium than in Italy, one must be very cautious when interpreting the absolute difference between the values of the indictor. This is because the share of Gestione Separata workers in total employment in Italy was proxied by the share of temporarily employed due to a lack of more direct data available in Eurostat OECD and ILOSTAT databses).

The CWTI indicator revealed minor differences in the contextualized inclusiveness of requirements pertaining to the minimum working-time/income achieved to be entitled to parental leave benefits in four countries that scored the same (zero) on Dobrotić and Blum's assessment. Interestingly, the average share of the part-time employed in countries that scored 1 on the original indicator was lower than the share of part-time employed in countries that scored 0 (28.2 vs $21.3 ; p=0.002)$. This could mean that the exclusion of the marginally employed coincides with a higher presence of this type of employment in the working population in the 16 countries. However, as part-time employment is not an ideal indicator for marginal employment, this result should be interpreted with caution as well.

\subsection{Citizenship-Based Parental Leave Entitlements}

For the first two citizenship-based entitlement criteria, the differences found in the contextualized inclusiveness between countries (that scored the same on the original indicators) were much smaller than for the employment-based entitlements. Furthermore, in contrast to employment-based leave entitlements, I found no relationship between the formal inclusiveness of policy regulations with respect to citizenship-based criteria and the relevant socio-economic context.

For the residency criterion, two countries scored the same (1 point) in Dobrotić and Blum's study. The contextualized CRI indicator for these countries was nearly 1 ( 0.997 for Croatia and 0.97 for Iceland). Such a close result was driven by a similar and very low percent of non-citizens in total population in both countries ( 0.01 vs 0.09 ) and a very close score on the permanent residency policy dimension in the MIPEX indicator in both countries (65 vs 62). Furthermore, I found no statistically significant difference between the average values of the MIPEX indicator and the share of non-citizens between countries that scored 1 and those that scored 0 in Dobrotic and Blum's classifications. As concerns the exclusion of some groups from citizenship-based entitlements, Croatia, Chechia, Denmark, Germany and Portugal originally received the same score (zero). The comparable data on the share of the excluded group(s) in the population 
was, unfortunately, available only for Germany (longterm unemployed) and Croatia (migrants). The CGI indicator was 0.99 and 0.98 for these countries, respectively, showing a marginal difference to formal inclusiveness for this citizenship-based criterion.

Among the countries that scored 0 points on the last original indicator by Dobrotić \& Blum, who assessed the presence of means-testing in the entitlement rules for citizenship-based benefits, the share of people that would not adhere to the means-testing criterion was large, leading to rather low values for contextualized inclusiveness for all of these countries, too. However, no statistically significant difference was found in the share of people with incomes above the poverty threshold (closest to the level of means-testing threshold) between countries that apply means-testing in citizenship-based entitlements and those that do not.

\subsection{Composite Index}

Overall, the values of the composite contextualized eligibility index modify the assessment of inclusivity (contextualized vs formal) for nearly all countries (Figure 1). While the lowest score still belongs to France (12) and the highest to Iceland and Slovenia (19), there is an additional 'winner' - Germany (19). The relative position of other countries in the ranking changes as the value of contextualized inclusiveness increases more strongly for some countries than for others.

\section{The 'Gender Dimension' in the Analysis of Contextualized Inclusiveness of Parental Leave Designs}

The original concept of the eligibility index and its nine dimensions of inclusiveness of parental leave benefits proposed by Dobrotić and Blum (2020) do not encompass the gender dimension. This was addressed sep- arately by the authors through classification of the parental leave systems into four categories of policy design: (1) gendered access (individual mothers' rights, which may be transferable to fathers in certain cases), (2) gender-neutral access (family rights or individual, fully transferable rights), (3) gender-sensitive access (family rights with less than one-third of non-transferable leave period and/or where a gender equality bonus is paid; individual, non-transferable rights with less than one third of the period being non-transferable) and (4) degendered access (individual, nontransferable rights or family rights with at least one-third of the leave period being non-transferable).

The first category was considered the least inclusive (for fathers/men), and the last one the most inclusive. However, the logic behind how these categories are identified (i.e., conceptualization of gender inclusiveness) is very different (and much more complex) than for other dimensions of inclusiveness. It is based not only on the (level of) strictness of the criteria for formal access to parental leave benefits for fathers (versus mothers), but also on the characteristics of leave regulations that ensure higher take-up of leaves by fathers or at least make it easier to exercise their rights to parental leaves (non-transferable individual rights for fathers and mothers are considered to be more inclusive than transferable rights). This approach to gender inclusiveness would therefore require a very different means of contextualization, one beyond the scope and space limitations of this article. On a positive note, this constitutes an avenue for future research.

Here, I only point out some ideas that could be considered. First, whenever access to parental benefits for fathers is conditioned by mothers fulfilling certain requirements (e.g., mothers having an employment contract, such as in the UK or formerly in Poland), the contextualization should take account of the share of partnered

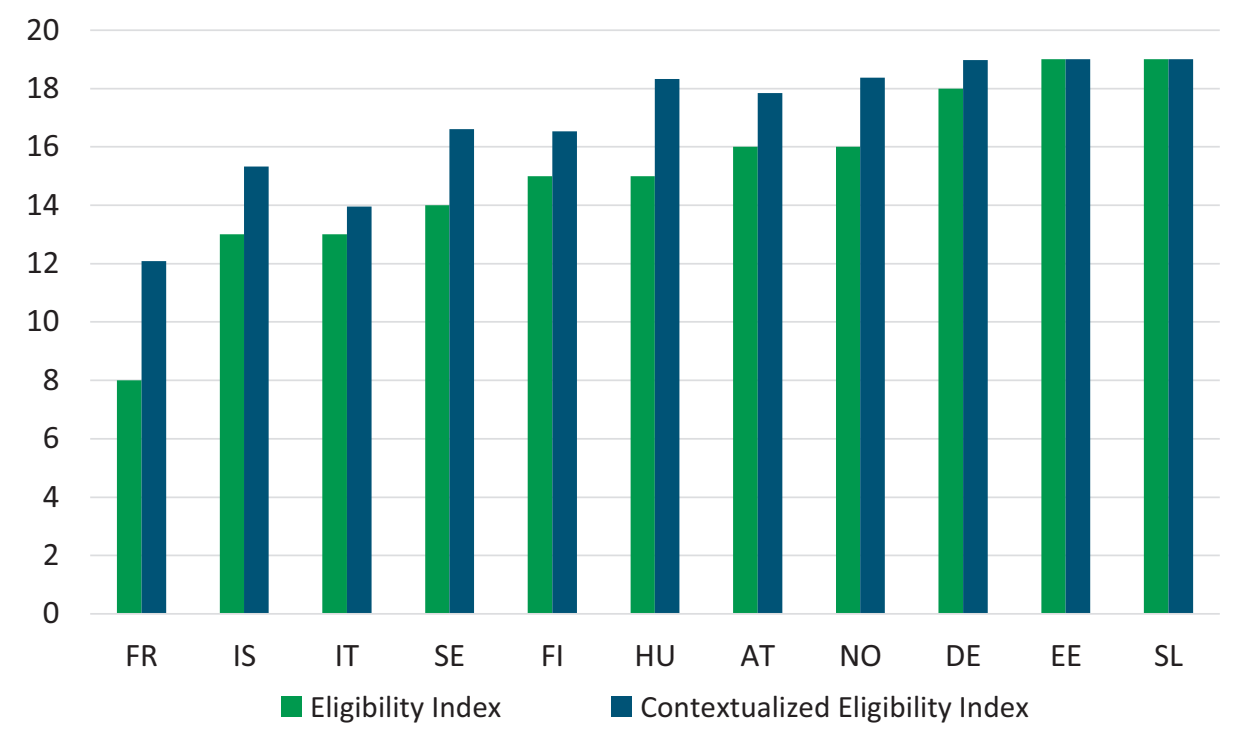

Figure 1. Formal and contextualized inclusiveness of parental leave benefits in eleven European countries-values for the Eligibility Index and Contextualized Eligibility Index (data for 2017). 
women that do not meet these requirements. Secondly, as mothers and fathers differ in employment characteristics (e.g., contract type, occupation, sector of employment, job tenure, working hours), the gender dimension in the analysis of contextualized inclusiveness of parental benefits could also be applied by disaggregating the contextualized indicators proposed in this article by gender. Finally, as the way Dobrotić and Blum (2020) approach the gender dimension touches upon the issue of enabling the higher take-up of parental leaves by fathers, the contextualization of the gender dimension could also extend into this aspect, as Javornik and Kurowska (2017) and Kurowska and Javornik (2019) did.

\section{Conclusion}

In this article I have presented a contextualized version of the indicators of formal inclusiveness proposed by Dobrotić and Blum (2020). The contextualization was based on incorporating, into the original indicators (based solely on formal regulations), the most relevant features of the socio-economic context. That context encompassed, in particular, the labour market structure (according to job tenure, employment stability, contract type, sector or economic profession, as well as population structure by citizenship and income) and in some cases also the institutional context (labour mar$\mathrm{ket} / \mathrm{migrant}$ law). The aim was to bring the comparative assessment of inclusiveness of parental leave benefits in European countries closer to the assessment of contextualized inclusiveness that primarily refers to the share of people that, in case of parenthood, would have access to parental leave benefits.

Applying the contextualized version of the eligibility indicators, I uncovered a far more diversified and nuanced landscape of contextualized inclusiveness of parental leave entitlements in Europe than the comparison of formal inclusiveness by Dobrotić and Blum (2020) suggested was the case. For nearly all dimensions of eligibility in employment-based parental leave entitlements, the homogenous groups of countries identified by Dobrotić and Blum (2020), which collectively had a relatively low level of formal parental leave benefit inclusiveness, were highly diversified in terms of contextualized inclusiveness. This finding is in line with previous research that showed greater differences in contextualized generosity of parental leave benefits in Europe (see, e.g., Bártová \& Emery, 2018).

This study has also shed light on the relationship between formal inclusiveness and the related country context. I found evidence, that in the case of two important aspects of eligibility rules of employment-based entitlements (related to job tenure and self-employment status), higher formal inclusiveness of parental leave benefit entitlements 'compensated,' to some extent, the 'less favourable' socio-economic context in these countries. In other words, higher formal inclusiveness of employment-based parental leave benefits was in these two cases more common in countries with higher shares of those social groups that, in the case of less inclusive regulations, would not have access to parental benefits.

What is more, the results provided additional evidence for the heterogeneity of opportunities created by parental leaves in Nordic countries, which are commonly treated as a monolith in terms of parental leave systems. The contextualization highlighted that Sweden, which is known for offering among the most gender equal parental leave entitlements in Europe (Ciccia \& Verloo, 2012; Dearing, 2016; Javornik \& Kurowska, 2017; Korpi, Ferrarini, \& Englund, 2013; Lohmann \& Zagel, 2016; Saxonberg, 2013), at the same time, has the least inclusive parental leave benefit opportunities among all the analysed countries when it comes to contextualized eligibility requirements related to job tenure and the criterion of non-interruptability of employment.

Lastly, this study has also revealed that, in contrast to employment-based parental leave entitlements, the socio-economic context is much less important for assessing the contextualized inclusiveness of citizenshipbased entitlements.

This study is not without limitations. First, the contextualized measures relate in some cases to the entire adult (in some cases working) population rather than to the population of potential parents only (i.e., men and women aged 20-49, as operationalized by O'Brien et al., 2020). Second, for some indicators, due to the unavailability of data, proxies for measuring the socio-economic context had to be chosen rather than direct measures. Both of these limitations, however, resulted from prioritizing the provision of easy-to-use indicators that can be calculated both for the past and in the future for all European countries by both academic and practiceoriented audiences.

The strength of the proposed approach lies in its applicability to other areas of care policy, including sick leave or ECEC entitlements. This is therefore an avenue for future research in the comparative analysis of contextualized inclusiveness of care policies in Europe. A desirable extension of the proposed approach to contextualized inclusiveness would be to incorporate a gender dimension into the analysis.

\section{Acknowledgments}

The author is grateful to three anonymous reviewers and the editors of the thematic issue, who gave excellent comments leading to the improvement of the article. This study was financed under the author's research grant no. 2019/35/B/HS5/02267 from the National Science Centre, Poland.

\section{Conflict of Interests}

The author declares no conflict of interests. 


\section{Supplementary Material}

Supplementary material for this article is available online in the format provided by the author (unedited).

\section{References}

Bardasi, E., \& Gornick, J. C. (2008). Working for less? Women's part-time wage penalties across countries. Feminist Economics, 14(1). https://doi.org/10.1080/ 13545700701716649

Bártová, A., \& Emery, T. (2018). Measuring policy entitlements at the micro-level: Maternity and parental leave in Europe. Community, Work and Family, 21(1), 33-52. https://doi.org/10.1080/13668803. 2016.1202196

Boeri, T., \& Jimeno, J. F. (2005). The effects of employment protection: Learning from variable enforcement. European Economic Review, 49(8). https://doi. org/10.1016/j.euroecorev.2004.09.013

Ciccia, R., \& Verloo, M. (2012). Parental leave regulations and the persistence of the male breadwinner model: Using fuzzy-set ideal type analysis to assess gender equality in an enlarged Europe. Journal of European Social Policy, 22(5), 507-528. https://doi. org/10.1177/0958928712456576

Clasen, J., \& Clegg, D. (2007). Levels and levers of conditionality: Measuring change within welfare states. In J. Clasen \& N. A. Siegel (Eds.), Investigating welfare state change: The "dependent variable problem" in comparative analysis. Cheltenham: Edward Elgar Publishing. https://doi.org/10.4337/ 9781847206916.00018

de la Porte, C., \& Emmenegger, P. (2017). The court of justice of the European Union and fixed-term work: Putting a brake on labour market dualization? Journal of European Social Policy, 27(3), 295-310. https:// doi.org/10.1177/0958928716684316

Dearing, H. (2016). Gender equality in the division of work: How to assess European leave policies regarding their compliance with an ideal leave model. Journal of European Social Policy, 26(3). https://doi.org/ $10.1177 / 0958928716642951$

Dobrotić, I., \& Blum, S. (2020). Inclusiveness of parentalleave benefits in twenty-one European countries: Measuring social and gender inequalities in leave eligibility. Social Politics: International Studies in Gender, State \& Society, 27(3), 588-614. https://doi.org/ $10.1093 / \mathrm{sp} / \mathrm{jxz} 023$

Gagliarducci, S. (2005). The dynamics of repeated temporary jobs. Labour Economics, 12(4), 429-448. https:// doi.org/10.1016/j.labeco.2005.05.001

Gielen, A. C., \& Tatsiramos, K. (2012). Quit behavior and the role of job protection. Labour Economics, 19(4). https://doi.org/10.1016/j.labeco.2012.05.002

Giesecke, J., \& Groß, M. (2003). Temporary employment: Chance or risk? European Sociological Review, 19(2), 161-177. https://doi.org/10.1093/esr/19.2.161
Haltiwanger, J., Scarpetta, S., \& Schweiger, H. (2014). Cross country differences in job reallocation: The role of industry, firm size and regulations. Labour Economics, 26. https://doi.org/10.1016/j.labeco.2013. 10.001

Horemans, J., Marx, I., \& Nolan, B. (2016). Hanging in, but only just: Part-time employment and in-work poverty throughout the crisis. IZA Journal of European Labor Studies, 5(1). https://doi.org/10.1186/ s40174-016-0053-6

Huddleston, T., Bilgili, Ö., Joki, A.-L., \& Vankova, Z. (2015). Migrant integration policy index 2015. Barcelona and Brussels: CIDOB and MPG. Retrieved from https:// www.mipex.eu/sites/default/files/downloads/files/ mipex-2015-book-a5.pdf

Javornik, J. (2014). Measuring state de-familialism: Contesting post-socialist exceptionalism. Journal of European Social Policy, 24(3), 240-257. https://doi.org/ $10.1177 / 0958928714525815$

Javornik, J., \& Kurowska, A. (2017). Work and care opportunities under different parental leave systems: Gender and class inequalities in Northern Europe. Social Policy and Administration, 51(4), 617-637. https:// doi.org/10.1111/spol.12316

Eurostat. (2020). Key figures on Europe-Statistics illustrated [Data set]. Retrieved from https:// ec.europa.eu/eurostat/web/products-statisticalbooks/-/ks-ei-20-001

Korpi, W., Ferrarini, T., \& Englund, S. (2013). Women's opportunities under different family policy constellations: Gender, class, and inequality tradeoffs in western countries re-examined. Social Politics, 20(1), 1-40. https://doi.org/10.1093/sp/jxs028

Koslowski, A., \& Kadar-Satat, G. (2018). Fathers at work: Explaining the gaps between entitlement to leave policies and uptake. Community, Work \& Family, 22(2), 129-145.

Kurowska, A., \& Javornik, J. (2019). Comparative social policy analysis of parental leave policies through the lens of the capability approach. In M. A. Yerkes, J. Javornik, \& A. Kurowska (Eds.), Social policy and the capability approach. Concepts, measurements and application (pp. 83-106). Bristol: Policy Press. https://doi.org/10.2307/j.ctvjf9v8g.10

Lohmann, H., \& Zagel, H. (2016). Family policy in comparative perspective: The concepts and measurement of familization and defamilization. Journal of European Social Policy, 26(1), 48-65. https://doi.org/10.1177/ 0958928715621712

McKay, L., Mathieu, S., \& Doucet, A. (2016). Parentalleave rich and parental-leave poor: Inequality in Canadian labour market based policies. Journal of Industrial Relations, 58(4), 543-562.

O’Brien, M., Connolly, S., \& Aldrich, M. (2020). Eligibility for parental leave in EU Member States. European Institute for Gender Equality. Retrieved from https://eige.europa.eu/publications/eligibilityparental-leave-eu-member-states 
O'Dorchai, S., Plasman, R., \& Rycx, F. (2007). The parttime wage penalty in European countries: How large is it for men? International Journal of Manpower, 28(7). https://doi.org/10.1108/01437720710 830061

OECD. (2020). OECD employment outlook 2020. Paris: OECD. Retrieved from https://www.oecd.org/els/ emp/EmploymentOutlook2020-chapter3.pdf

Pages, C., \& Micco, A. (2012). The economic effects of employment protection: Evidence from international industry-level data (IDB Working Paper No. 495). Washington, DC: Inter-American Development Bank. https://doi.org/10.2139/ssrn.1820068
Ray, R., Gornick, J. C., \& Schmitt, J. (2010). Who cares? assessing generosity and gender equality in parental leave policy designs in 21 countries. Journal of European Social Policy, 20(3), 196-216. https://doi.org/ 10.1177/0958928710364434

Sanz, Y. R. (2011). Landing a permanent contract in Spain: Do job interruptions and employer diversification matter? Manchester School, 79(6). https://doi.org/ 10.1111/j.1467-9957.2011.02220.x

Saxonberg, S. (2013). From defamilialization to degenderization: Toward a new welfare typology. Social Policy and Administration, 47(1), 26-49. https://doi.org/ 10.1111/j.1467-9515.2012.00836.x

\section{About the Author}

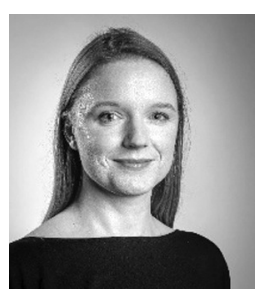

Anna Kurowska is an Associate Professor at the Faculty of Political Science and International Studies and Vice-Head of the Interdisciplinary Centre for Labour Market and Family Dynamics (LABFAM) at the University of Warsaw. She is a political scientist and economist with a particular expertise in comparative care regimes, family policy, female employment, gendered division of labour, work-life balance and the capability approach applied to social policy analyses. 